\title{
FUZZY MODELLING IN RISK ASSESSMENT OF OIL AND GAS PRODUCTION ENTERPRISES' ACTIVITY
}

\author{
Iryna FADYEYEVA ${ }^{1}$, Oksana GRYNIUK ${ }^{2}$ \\ Ivano-Frankivsk National Technical University of Oil and Gas, Ukraine
}

\begin{abstract}
The purpose of the article is to develop a fuzzy model of assessment of risks of activities of oil and gas production enterprises. Methodology. Due to a large number of factors, influencing the probability of risk occurrence, and in order to obtain a comprehensive indicator during the research, we have applied a fuzzy cascade model of the Mamdani type. Research results. In the conditions of instability and constant uncertainty of oil and gas production processes, identification and forecasting of the occurrence of risks of operations of oil and gas production enterprises by traditional mathematical methods of modelling provide no required reliability and accuracy of forecasting. In this regard, we propose an integral assessment and application of the fuzzy logic methodology for obtaining the required results for the adoption of effective managerial decisions. Despite the complexity of the mathematical apparatus, risk assessment on the basis of the theory of fuzzy sets makes it possible to create a sufficiently flexible model, which will operate with a large number of input arguments and give as a resultant variable a value, which can be considered to be objective with some degree of approximation. Practical importance. The step-by-step addition of each group of risk factors to the model allows obtaining reliable results of the probability of occurrence of risk events on a real-time basis, which significantly reduces the company's losses. Value/originality. According to the results of the research, the Mamdani-type fuzzy cascade model of the assessment of risks of the activities of the oil and gas production enterprises is developed for the first time.
\end{abstract}

Key words: risk assessment, risk factors, fuzzy logic, uncertain data, oil and gas production enterprise.

JEL Classification: C63, G32

\section{Introduction}

The oil and gas production enterprise is a typical example of a complex system. The complexity of the management of such an enterprise, in particular, the management of risks, associated with the activities of this entity, is due to the fact that it is a dynamic system with a set of ambiguous data. According to M.V. Nikolaichuk, the dynamic nature of the enterprise's operating environment and internal business processes requires management to make managerial decisions, primarily in a context of uncertainty, which, in the current market, contributes to the implementation of risk factors (Nikolaichuk, 2013).

In this regard, there is an objectiveneed to implement the risk controlling system into the enterprise management system. The risk controlling system should ensure the adaptation of enterprise to changing internal and external conditions while maintaining certain stability and ensuring stable operation (Yakupova \& Magomedova, 2008). We consider risk controlling as a controlling subsystem, designed to provide the risk management of the company with the relevant information on risks, to develop a methodology, which is optimal for the analysis and assessment of enterprise risks by risk management system in order to support management in the process of making operational and strategic decisions.

The main difficulty in assessing the risk is the heterogeneity of the input data on the current state of the equipment (underground and ground), information on maintenance, the environmental consequences of oil production, etc. The task becomes significantly complicated by the dynamics of risk-forming factors, which determine the current level of risk of the activities of the oil and gas production enterprise. Analysis of modern methods of risk assessment has shown that there is a need to develop models for assessing the risks of the enterprises' activities, which could take into account the uncertainty and vagueness of information on key risk-forming factors, the limitations of statistical information, expert opinion, etc.

First of all, when assessing the risks of an enterprise, it is required to investigate the dependencies between risk factors. Statistical methods for the determination of dependencies are used when there is statistical data for

\footnotetext{
Corresponding author:

${ }^{1}$ Department of Finance, Ivano-Frankivsk National Technical University of Oil and Gas.

Email: i.fadyeyeva@gmail.com

${ }^{2}$ Department of Finance, Ivano-Frankivsk National Technical University of Oil and Gas.

Email: oksankagr@gmail.com
} 
past periods, expert methods are used when there is no statistical information available. If there is no statistical data to describe certain risk factors or it is difficult to determine the dependencies between them in the form of a mathematical model, it is offered to use fuzzy logic apparatus for its assessment (Babak, 2008). Fuzzy logic tools make it possible to assess the level of risk on the basis of quantitative and qualitative indicators, expert knowledge; use fuzzy input data; describe the indicators, the values of which are continuously changing in time; take into account the nonlinearity of development of processes; not clearly formulate the assessment criteria.

Due to the facts mentioned above, the necessity for the formation of the model of assessment of risk level of oil and gas production enterprises on the basis of the fuzzy logic inference algorithm is justified, which, in our opinion, is one of the tasks of its risk controlling system. The primary task in the formation of the risk assessment model is to determine the list of input factors.

\section{Identification of risks and risk-forming factors}

The occurrence of risks is possible upon the availability of causes (processes, phenomena), which contribute to its occurrence. Such phenomena are usually named as risk-forming factors. Based on the analysis, we identified six groups of risks of activities of oil and gas production enterprises and its respective risk factors (Gryniuk, 2016).

It is obvious that the given list of risk-forming factors does not pretend to be absolutely correct and complete. In addition, it fully reveals the possible causes of the occurrence of risk events at oil and gas production enterprises in comparison with those, which can be found in research works of scientists in this area of research. Expert assessment is carried out for quantitative assessment and analysis of the impact of factors on the level of risk of the enterprise's activities. Experts have determined the probability of the occurrence of a riskforming factor and the level of negative consequences caused by it (Gryniuk, 2016). For the purpose of reliable determination of significant and screening of nonsignificant factors of specific risks of the activities of oil and gas production enterprises, a full factorial experiment of $2^{k}$ type is used. According to the results of the experiment, 11 non-significant factors are identified; it is suggested to exclude it from the risk assessment model of the activities of oil and gas production enterprises. Other factors are the input variables of the model, formed on the basis of the fuzzy set theory.

\section{Fundamentals of application of fuzzy logic for risk assessment}

It should be noted, that the potential of working with the fuzzy logic mechanism has not yet been achieved in the field of risk assessment of oil and gas production enterprises, thus, in our opinion, its application is relevant.

In the source (Zadeh, 1976), the fuzzy model is represented as a set of linguistic rules, each of which is defined using the tuple $<T, U, X, Y, I, F>$, where $T$ is the set of linguistic terms, $U$ is the set of universes of fuzzy variables, $X$ is the set of input data, $Y$ is the set of initial data, and $I$ is the method of fuzzy implication, $F$ is the methods of fuzzification and defuzzification.

According to the methodology of the theory of fuzzy sets and fuzzy logic, data flows undergo the appropriate processing - fuzzification and defuzzification (Fig. 1).

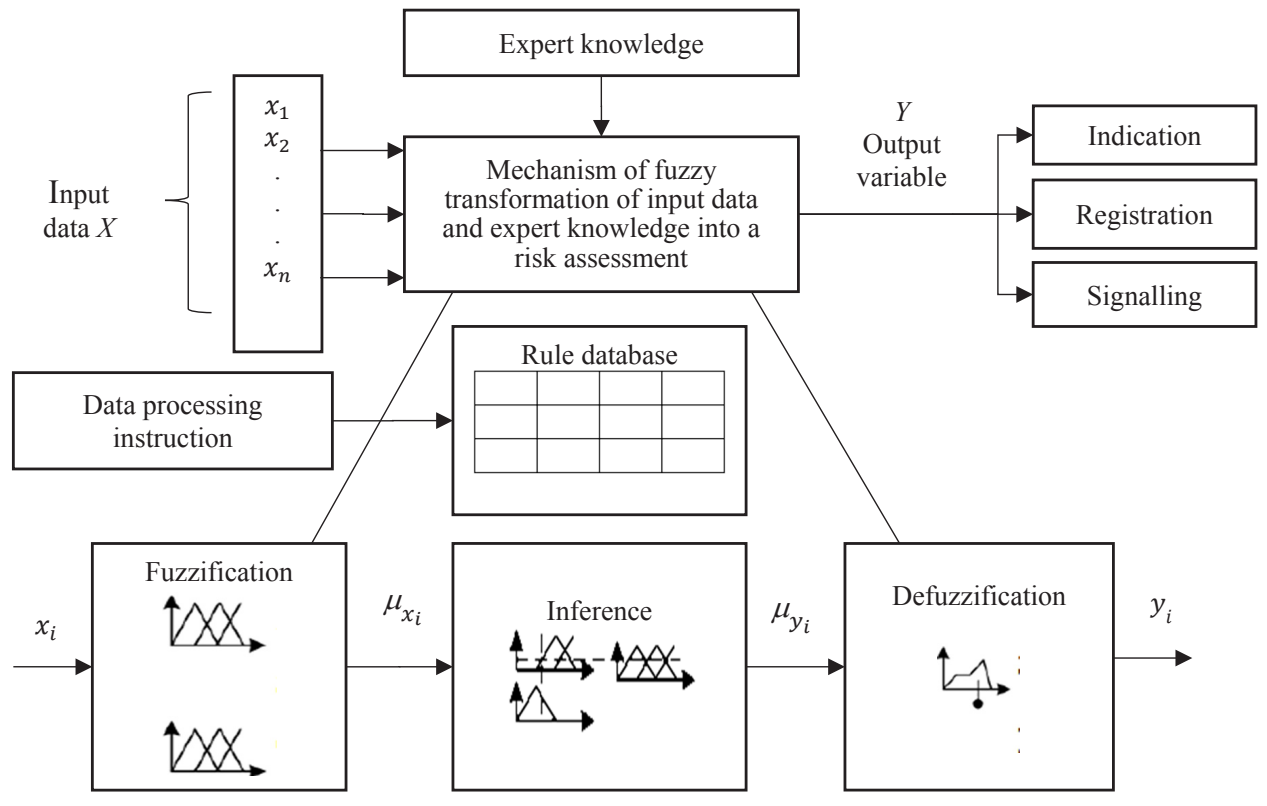

Fig. 1. Components of controller with fuzzy algorithm:

$x_{1}, y_{1}$-membership functions $x_{1}, y_{1}$ respectively

Source: developed by the author on the basis of Leonenkov, 2005 
In the source (Leonenkov, 2005) it is stated that several algorithms are proposed to obtain conclusions in systems of fuzzy inference, the description of which is based on the division of the output process by a series of successive stages:

1. Formation of the rule database of fuzzy inference systems.

2. Fuzzification of input variables.

3. Aggregation of sub-conditions in fuzzy conditionaction rules.

4. Activation or composition of sub-conclusions in fuzzy condition-action rules.

5. Accumulation of conclusions of fuzzy conditionaction rules.

6. Defuzzification of output variables.

Variables, used in fuzzy statements of the subconditions of fuzzy inference rules are named as input linguistic variables, in its turn, variables, used in statements of sub-conclusions, are named as output linguistic variables. The corresponding term sets and membership functions must be given to each variable.

The information at the input is transformed so that the tasks of linguistic variables allow defining a control rule and a linguistic variable, which corresponds to the output value of the fuzzy controller.

Input information processing consists of the following basic procedures:

- fuzzification, that is, the determination of linguistic variables $X$ and its membership functions $\mu(x)$, where $\mathrm{x}$ is a continuous base variable; $x \in X ; 0 \leq \mu(x) \leq 1$;

- interference, that is, the determination of control rules and linguistic variable corresponding to the signal at the output;

- defuzzification, that is, the transformation of linguistic variables at the output into a continuous signal.

When using the fuzzy set theory, selection of membership functions is very important. The main types of membership functions are piecewise linear (triangular, trapezoidal), Z-shaped, $S$-shaped, and $P$-shaped membership functions. For the formation of a fuzzy model of risk assessment of activities of oil and gas enterprises, we have chosen a triangular membership function because it requires only three parameters to be determined, and it is calculated faster than the membership functions of other types.

It should be noted that the above stages of fuzzy inference can be implemented in an ambiguous way since it includes separate parameters, which must be fixed or specified. Thus, the choice of specific variants of the parameters of each stage determines an algorithm, which fully implements the fuzzy inference in the systems of fuzzy production rules (Leonenkov, 2005). As yet, several algorithms of fuzzy inference have been proposed: Mamdani, Tsukamoto, Sugeno and Larsen. The formation of the rules database is proposed to be carried out based on the Mamdani algorithm. The choice of Mamdani's fuzzy inference system is explained by the ease of interpretation of the membership functions using the linguistic variables and by the obtaining of clear number output (Seredyuk, 2011).

\section{Generation of Fuzzy Models Based On Experimental Data}

Data for logical processing is received from both fuzzification in the form of justified fuzzy ranges of controlled values of input factors, and from the rule database, that is, from the user (Fig. 1). Data is received from the user as a set of logical rules of the Mamdani type, which have the following structure:

$R: \operatorname{IF}\left(A_{1}, A_{2}, \ldots, A_{n}\right) \operatorname{THEN}\left(B_{1}, B_{2}, \ldots, B_{m}\right)$,

where $A_{1}, A_{2}, \supset, A_{n}$ - antecedent;

$n$ - number of input variables;

$B_{1}, B_{2}, \supset, B_{m}$ - consequent,

$\mathrm{m}$ - number of output variables.

The number of terms, used to assess the risk factors, is taken to be equal to three, namely: $\mathrm{H}-$ "high", $\mathrm{M}$ "medium", L - "low". The total number of individual fuzzy rules $\mathrm{N}$ in the rules database is determined by the product:

$$
N=l_{1} \times l_{2},
$$

where $l_{1}, l_{2}$ - number of terms of output data $X_{1}, X_{2}$. We take the number of terms for each input variable to be $l_{1}=l_{2}=3$, then $N=9$. The number of linguistic variables for the output value $Y_{s}$ is equal to three. The initial point for the development of the appropriate Mamdani-type rule database is a linguistic description of the process of risk formation of the production and economic activity of oil and gas production enterprises in the context of the uncertainty of the business environment. The rules directly describe the dependence of the level of risk $(R R)$ on changes in risk factors at oil and gas production enterprises.

The general form of the set of fuzzy rules $R^{(k)}, k=1,2, \ldots, N$ is as follows (Shtovba, 2007):

$$
\begin{aligned}
& R^{(k)}: \text { IF } x_{1} \text { is } A_{1}^{k} \text { and } x_{2} \text { is } A_{2}^{k} \text { and ... and } x_{n} \text { is } A_{n}^{k} \text { THEN } \\
& y_{1} \text { is } B_{1}^{k} \text { and } y_{2} \text { is } B_{2}^{k} \text { and } \supset \text { and } y_{m} \text { is } B_{m}^{k} \text {, }
\end{aligned}
$$$$
\text { where } R^{(k)}(k=1,2, \ldots, N) \text { - } k \text {-th rule; }
$$

$A_{i}^{k}, B_{j}^{k}$ - linguistic terms - fuzzy subsets, which are defined by the piecewise linear triangular membership functions,

$$
\begin{aligned}
& A_{i}^{k} x_{i} R, i=1,2, \ldots, n ; \\
& B_{j}^{k} y_{j} R, j=1,2, \ldots, m ;
\end{aligned}
$$

$x_{1}, x_{2}, \supset, x_{n}$ - input variables of the linguistic model, in particular

$$
\begin{aligned}
& \left(x_{1}, x_{2}, \ldots, x_{n}\right)^{T}=x X_{1}, X_{2}, \ldots, X_{n}, \\
& y_{1}, y_{2}, \supset, y_{m}-\text { output variables of } k \text {-th rule, in } \\
& \text { particular } \\
& \quad\left(y_{1}, y_{2}, \ldots, y_{m}\right)^{T}=y Y_{1}, Y_{2}, \ldots, Y_{m}, \\
& R \text { - the set of real numbers. }
\end{aligned}
$$


Let us also assume that $A_{i}^{k}, B_{j}^{k}$ are numbered. The symbols $X_{i}, i=1,2, \ldots, n$ and $Y_{j}, j=1,2, \ldots, m$ are respectively marked spaces of the input and output variables.

The rules contain expert knowledge of what to do if one of the properties, formulated during fuzzification, has become valid. The results are combined (aggregated) by the operators AND and OR.

The operator "AND" (conjunction) is determined by the following relation:

$$
\mu_{x_{1} \text { and } x_{2}}(x)=\min \left\{\mu_{x_{1}}(x) ; \mu_{x_{2}}(x)\right\},
$$

and operator "OR" (disjunction) is determined by the following relation: $\mu_{X_{1} \text { OR } X_{2}}(x)=\max \left\{\mu_{X_{1}}(x) ; \mu_{X_{2}}(x)\right\}$.

Logical conclusion will be performed according to the first relation. For the investigated object (oil and gas production enterprises), there have been proposed the spaces of input variables (risk factors) and output variables (risk levels), containing the finite set of linguistic terms with triangular membership functions (trimf), the triangular membership function has the following analytic expression (Shtovba, 2007):

$$
\mu(x)=\left\{\begin{array}{l}
0, x \leq \text { аабо } x \geq c, \\
\frac{x-a}{b-a}, a<x \leq b, \\
\frac{c-x}{c-b}, b<x<c,
\end{array}\right.
$$

where $(a, c)$ is the fuzzy set carrier - a pessimistic estimation of the fuzzy number; $b$ is the maximum coordinate - optimistic estimation of the fuzzy number.

Membership functions are built by the method of processing of expert information in the environment of Fuzzy Logic Toolbox (MATLAB).

The linguistic model for the risk detection system with $\mathrm{n}$ inputs and 1 output will be found as a set of linguistic rules with all possible combinations of fuzzy values in the antecedent. For this purpose, let us take that the specific rules $R^{(k)}, k=1,2, \ldots, N$ are interconnected by an operator "or" and it is taken into account that $y_{1}, y_{2}, \supset, y_{m}$ are mutually independent. This allows using fuzzy rules with a scalar output for two input variables and one output variable in the following form:

$$
R^{(k)} \text { : IF } x_{1} \text { is } A_{1}^{k} \text { and } x_{2} \text { is } A_{2}^{k} \text { THEN y is } B^{k} \text {, }
$$

For linguistic terms $A_{i}^{k}=\{L, M, H\}$ and $B_{j}^{k}=\{L, M, H\}$, the rule database of the Mamdani-type will have the form shown in Table 1.

Table 1

Rule database of the Mamdani-type $\mathbf{R D}^{(1)}$

\begin{tabular}{|c|c|c|c|c|}
\hline \multicolumn{2}{|c|}{$Y^{(1)}$} & \multicolumn{3}{c|}{$x_{1}$} \\
\cline { 3 - 5 } & & $\mathrm{L}$ & $M$ & $\mathrm{H}$ \\
\hline \multirow{3}{*}{$x_{2}$} & $\mathrm{~L}$ & $\mathrm{~L}$ & $\mathrm{~L}$ & $\mathrm{M}$ \\
\cline { 2 - 5 } & $\mathrm{M}$ & $\mathrm{L}$ & $\mathrm{M}$ & $\mathrm{H}$ \\
\cline { 2 - 5 } & $\mathrm{H}$ & $\mathrm{M}$ & $\mathrm{H}$ & $\mathrm{H}$ \\
\hline
\end{tabular}

Based on the rule database, a linguistic model is formulated out of 9 rules:

$R^{(1)}: \operatorname{IF} x_{1}$ is $\mathrm{L}$ and $x_{2}$ is $L$ THEN $Y^{(1)}$ is $L$,

$R^{(2)}: \operatorname{IF} x_{1}$ is $M$ and $x_{2}$ is $L$ THEN $Y^{(1)}$ is $L$,

$R^{(3)}: \operatorname{IF} x_{1}$ is $H$ and $x_{2}$ is $L$ THEN $Y^{(1)}$ is $M$,

$R^{(4)}: \operatorname{IF} x_{1}$ is $L$ and $x_{2}$ is $M$ THEN $Y^{(1)}$ is $L$,

$R^{(5)}$ : IF $x_{1}$ is $M$ and $x_{2}$ is $M$ THEN $Y^{(1)}$ is $M$,

$R^{(6)}:$ IF $x_{1}$ is $H$ and $x_{2}$ is $M$ THEN $Y^{(1)}$ is $H$,

$R^{(7)}: \operatorname{IF} x_{1}$ is $L$ and $x_{2}$ is $H$ THEN $Y^{(1)}$ is $M$,

$R^{(8)}:$ IF $x_{1}$ is $M$ and $x_{2}$ is $H$ THEN $Y^{(1)}$ is $H$,

$R^{(9)}: \operatorname{IF} x_{1}$ is $H$ and $x_{2}$ is $H$ THEN $Y^{(1)}$ is $H$.

The antecedents of the rules contain a set of conditions for the occurrence of risk factors, while the consequences contain conclusions about the level of risk. For cases, where the number of risk factors is more than two, the number of rules in the knowledge base can be reduced by identifying the dominant input variables, non-dominant input variables and input variables for optimization. This is achieved by applying the cascade method (Fig. 2) of the synthesis of rules.

If for example, risk factors are equal to 4 , then the rule database, which is given in Table 2 , should be supplemented by two rule databases: $\mathrm{RD}^{2}$ and $\mathrm{RD}^{3}$.

Table 2

Rule database of the Mamdani-type $\mathbf{R D}^{(2)}$

\begin{tabular}{|c|c|c|c|c|}
\hline \multicolumn{2}{|c|}{$Y^{(2)}$} & \multicolumn{3}{c|}{$Y^{(1)}$} \\
\cline { 3 - 5 } & $\mathrm{L}$ & $\mathrm{L}$ & $\mathrm{M}$ & $\mathrm{H}$ \\
\hline \multirow{3}{*}{$x_{3}$} & $\mathrm{~L}$ & $\mathrm{~L}$ & $\mathrm{M}$ & $\mathrm{M}$ \\
\cline { 2 - 5 } & $\mathrm{M}$ & $\mathrm{M}$ & $\mathrm{H}$ & $\mathrm{H}$ \\
\cline { 2 - 5 } & $\mathrm{H}$ & $\mathrm{H}$ \\
\hline
\end{tabular}

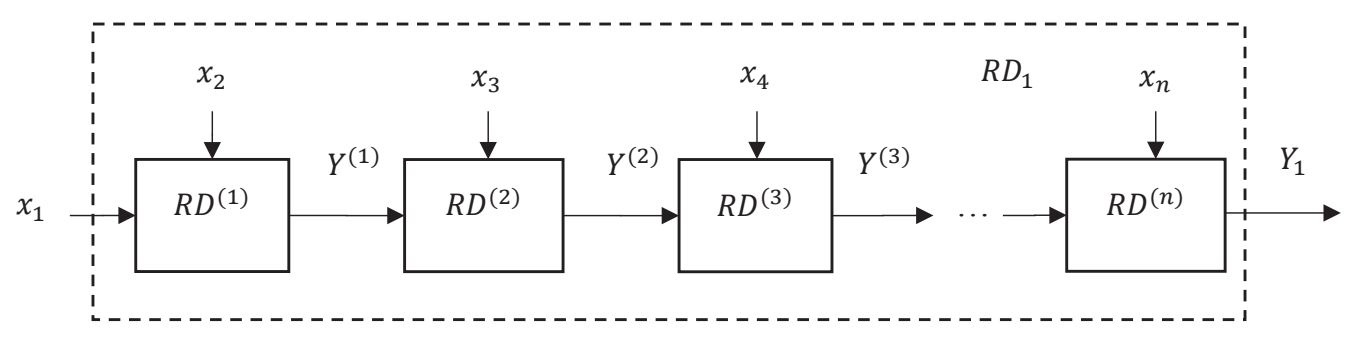

Fig. 2. Cascade method of formation of rule database $\boldsymbol{R} \boldsymbol{D}^{(1)}$

Source: Source: the authors' own development 
Table 3

Rule database of the Mamdani-type $\mathrm{RD}^{(3)}$

\begin{tabular}{|c|c|c|c|c|}
\hline \multicolumn{2}{|c|}{$Y^{(3)}$} & \multicolumn{3}{c|}{$Y^{(2)}$} \\
\cline { 3 - 5 } & $\mathrm{L}$ & $\mathrm{L}$ & $\mathrm{L}$ & $\mathrm{H}$ \\
\hline \multirow{3}{*}{$x_{4}$} & $\mathrm{M}$ & $\mathrm{L}$ & $\mathrm{L}$ & $\mathrm{M}$ \\
\cline { 2 - 5 } & $\mathrm{H}$ & $\mathrm{M}$ & $\mathrm{H}$ & $\mathrm{H}$ \\
\cline { 2 - 5 } & $\mathrm{H}$ & $\mathrm{H}$ \\
\hline
\end{tabular}

Based on the rule databases $\mathrm{RD}(2)$ and $\mathrm{RD}(3)$, a linguistic model is formulated out of 18 rules:

$$
\begin{aligned}
& R^{(10)}: \text { IF } Y^{(1)} \text { is } L \text { and } x_{3} \text { is } L \text { THEN } Y^{(2)} \text { is } L, \\
& R^{(11)}: \text { IF } Y^{(1)} \text { is } M \text { and } x_{3} \text { is } L \text { THEN } Y^{(2)} \text { is } L, \\
& R^{(12)}: \text { IF } Y^{(1)} \text { is } H \text { and } x_{3} \text { is } L \text { THEN } Y^{(2)} \text { is } M, \\
& R^{(13)}: \text { IF } Y^{(1)} \text { is } L \text { and } x_{3} \text { is } M \text { THEN } Y^{(2)} \text { is } L, \\
& R^{(14)}: \text { IF } Y^{(1)} \text { is } M \text { and } x_{3} \text { is } M \text { THEN } Y^{(2)} \text { is } M, \\
& R^{(15)}: \text { IF } Y^{(1)} \text { is } H \text { and } x_{3} \text { is } M \text { THEN } Y^{(2)} \text { is } H, \\
& R^{(16)}: \text { IF } Y^{(1)} \text { is } L \text { and } x_{3} \text { is } H \text { THEN } Y^{(2)} \text { is } M, \\
& R^{(17)}: \text { IF } Y^{(1)} \text { is } M \text { and } x_{3} \text { is } H \text { THEN } Y^{(2)} \text { is } H, \\
& R^{(18)}: \text { IF } Y^{(1)} \text { is } H \text { and } x_{3} \text { is } H \text { THEN } Y^{(2)} \text { is } H, \\
& R^{(19)}: \text { IF } Y^{(2)} \text { is } L \text { and } x_{4} \text { is } L \text { THEN } Y^{(3)} \text { is } L, \\
& R^{(20)}: \text { IF } Y^{(2)} \text { is } M \text { and } x_{4} \text { is } L \text { THEN } Y^{(3)} \text { is } L, \\
& R^{(21)}: \text { IF } Y^{(2)} \text { is } H \text { and } x_{4} \text { is } L \text { THEN } Y^{(3)} \text { is } M, \\
& R^{(22)}: \text { IF } Y^{(2)} \text { is } L \text { and } x_{4} \text { is } M \text { THEN } Y^{(3)} \text { is } L, \\
& R^{(23)}: \text { IF } Y^{(2)} \text { is } M \text { and } x_{4} \text { is } M \text { THEN } Y^{(3)} \text { is } M, \\
& R^{(24)}: \text { IF } Y^{(2)} \text { is } H \text { and } x_{4} \text { is } M \text { THEN } Y^{(3)} \text { is } H, \\
& R^{(25)}: \text { IF } Y^{(2)} \text { is } L \text { and } x_{4} \text { is } H \text { THEN } Y^{(3)} \text { is } M, \\
& R^{(26)}: \text { IF } Y^{(2)} \text { is } M \text { and } x_{4} \text { is } H \text { THEN } Y^{(3)} \text { is } H, \\
& R^{(27)}: \text { IF } Y^{(2)} \text { is } H \text { and } x_{4} \text { is } H \text { THEN } Y^{(3)} \text { is } H .
\end{aligned}
$$

Each rule of this knowledge base simulates one type of risk.

The structure of the output fuzzy ranges is similar to the input ones, that is: the input variables are the probability of occurrence of the risk factor: "low", "medium", "high" and the degree of its negative impact: "insignificant", "moderate", "significant"; output data of inference - the level of risk: "low", "medium", "high". The rules regulate the interrelation of the fuzzification data with the data of logical processing and are clear statements. Operations IF (condition) and THEN (action) works with fuzzy data, so, although the rule is clear, the result can only be fuzzy. That is, the data of logical processing is fuzzy data. Operations over the data are carried out by operators, which convert the intermediate results into the actions of fuzzy outputs.

By using the formulated risk detection rules, the value of the output variable $\mathrm{Y}$ can be obtained. In this regard, it is required to use the function of the membership of the variable $\mathrm{Y}$ in the set, created as a result of the logical conclusion operation over the sets, included in the rule system (5). The operation "and" in the rules (5) corresponds to the intersection of sets, and the result of applying all the rules corresponds to the operation of the union of sets (Pupkov, Egupov, \& Gavrilov, 2002).

The membership function for the union of two sets, for example, $M$ and $L$ (rule $\mathrm{R}^{(2)}$ ), is as follows:

$$
\mu_{x_{1} \cap x_{2}}=\min \left(\mu_{x_{1}}, \mu_{x_{2}}\right) \text {, }
$$

i.e., each value of the function of the membership of intersection of the sets is equal to the smallest value of the two ones, placed in the expression (6) in the brackets (Uskov \& Kuzmin, 2004).

The membership function for the intersection of the same sets has the following form (Uskov \& Kuzmin, 2004):

$$
\mu_{x_{1} \cup x_{2}}=\max \left(\mu_{x_{1}}, \mu_{x_{2}}\right) \text {. }
$$

The membership functions for each of the sets $L$, $M, H$, included in the fuzzy variable $Y$ in the rules (4) can be written as follows (Rutkovskaya, Pilinskiy, \& Rutkovskiy, 2006):

$$
\begin{aligned}
& \mu_{R^{(1)}}\left(Y^{(1)}\right)=\min \left\{\mu_{Y_{1}^{(1)}}\left(Y^{(1)}\right), \min \left(\mu_{x_{1}^{(1)}}\left(x_{1}\right), \mu_{x_{2}^{(1)}}\left(x_{2}\right)\right)\right\}, \\
& \mu_{R^{(2)}}\left(Y^{(1)}\right)=\min \left\{\mu_{Y_{2}^{(1)}}\left(Y^{(1)}\right), \min \left(\mu_{x_{1}^{(2)}}\left(x_{1}\right), \mu_{x_{2}^{(2)}}\left(x_{2}\right)\right)\right\}, \quad(8) \\
& \ldots \ldots \ldots \ldots \ldots \ldots \ldots \ldots \ldots \ldots \ldots \ldots \ldots \ldots \ldots \ldots \ldots \ldots \ldots \\
& \mu_{R^{(9)}}\left(Y^{(1)}\right)=\min \left\{\mu_{Y_{9}^{(1)}}\left(Y^{(1)}\right), \min \left(\mu_{x_{1}^{(9)}}\left(x_{1}\right), \mu_{x_{2}^{(9)}}\left(x_{2}\right)\right)\right\} .
\end{aligned}
$$

In this case, each of the nine equations corresponds to one of the rules (4).

The resulting membership function for $Y^{(1)}$, obtained after applying all nine rules, has been found in accordance with (7) as a union of the membership functions of all rules (4):

$$
\mu_{R}\left(Y^{(1)}\right)=\max \left\{\mu_{R^{(1)}}\left(Y^{(1)}\right), \mu_{R^{(2)}}\left(Y^{(1)}\right), \mu_{R^{(3)}}\left(Y^{(1)}\right), \ldots, \mu_{R^{(9)}}\left(Y^{(1)}\right)\right\} .
$$

The results of the inference are subject to defuzzification. Having fuzzy ranges, it is required to get the result, which is clear for the computer and the user. The calculation of the variable $Y^{(1)}$ at the output is made for each separate input variable, for which the membership function is $\mu_{x_{i}}>0$.

The logical conclusion is performed in accordance with the relation (1). The value of $Y^{(1)}$ is calculated using the minimax method of "centroid" (Mamdani method) or on the basis of the probabilistic interpretation of the theory of fuzzy sets, when the value $Y^{(1)}$ can be obtained using the following formula by analogy with mathematical expectations (Rutkovskaya, Pilinskiy, \& Rutkovskiy, 2006):

$$
Y^{(1)}=\frac{\int_{Y_{\min }^{(1)}}^{Y_{\max }^{(1)}} Y^{(1)} \mu\left(Y^{(1)}\right) d Y^{(1)}}{\int_{Y_{\min }^{(1)}}^{Y_{\max }^{(1)}} \mu\left(Y^{(1)}\right) d Y^{(1)}} .
$$

Each rule database $\mathrm{RD}^{(\mathrm{i})}$ forms information on the presence of risk $R\left(Y_{i}\right), i=1,2, . ., 6$, i.e.

$$
R\left(Y^{(1)}\right)=Y^{(1)} \cup Y^{(2)} Y^{(3)} \cup Y^{(4)} Y^{(5)} \cup Y^{(6)} .
$$

Then, the assessment of risk $R$ for oil and gas production enterprises, formed by each rule database $\mathrm{RD}$ (Fig. 3), will be as follows:

$$
R(Y)=Y 1 \cup Y 2 \cup Y 3 \cup Y 4 \cup Y 5 \cup Y 6 \text {. }
$$

The criterion for the risk of production and economic activity of oil and gas production enterprises is the value $R \in[0,1]$. The greater is the value of this criterion, the much more risk. Risk factors are indicated by $X_{1}, X_{2}, .$. , $X_{n}$. Then the model of risks of production and economic 


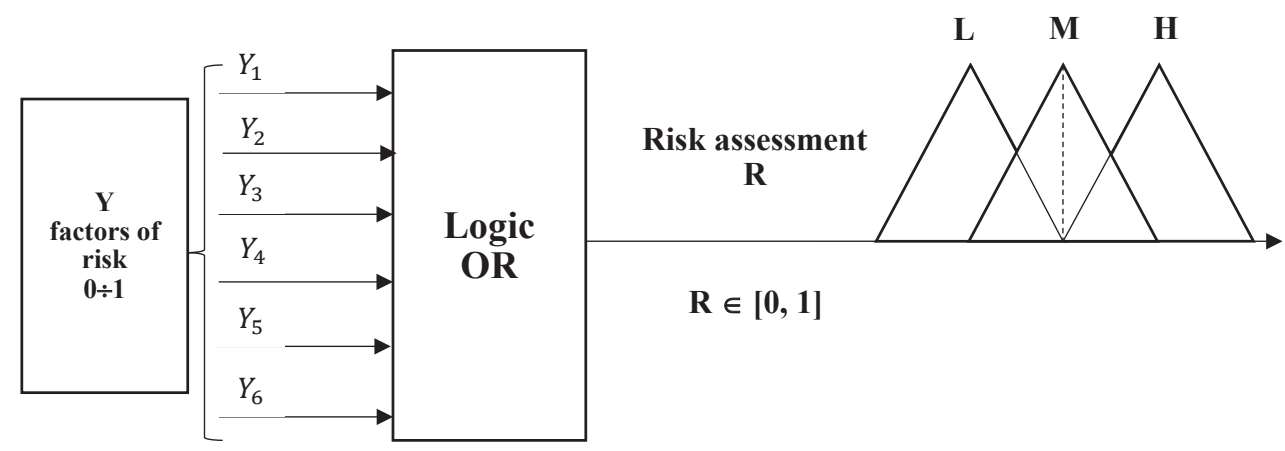

Fig. 3. Structure of inputs and outputs of the system of identification or risks of activities of oil and gas production enterprises

Source: the authors' own development

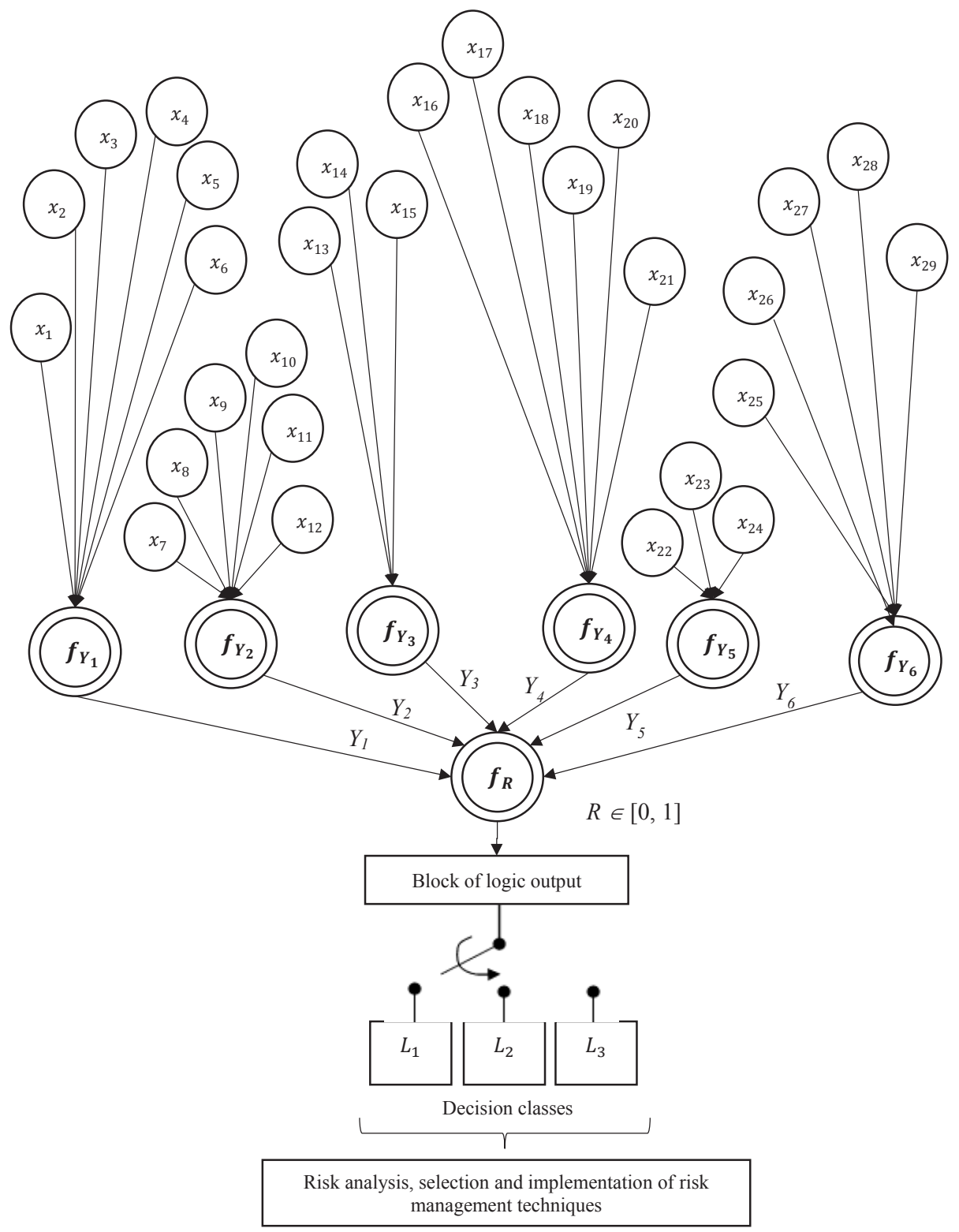

Fig. 4. The hierarchical structure of the risk factors of production and economic activity of oil and gas production enterprises

Source: the authors' own development 
activity of oil and gas production enterprises is presented as a functional mapping of the following form:

$$
X=\left(x_{1}, x_{2}, \ldots, x_{n}\right) \rightarrow R \in[0,1],
$$

where $\mathrm{X}$ - vector of risk factors.

The general hierarchical structure of the risk factors of production and economic activity of oil and gas production enterprises is presented in Fig. 4 in the form of a logical conclusion tree.

Elements of logical conclusion:

- the root of the tree - the risk of production and economic activity of the oil and gas production enterprises in the conditions of the uncertainty of business environment $(\mathrm{R})$;

- terminal vertices - individual risk factors $\left(x_{1}, x_{2}, . ., x_{29}\right)$; - non-terminal vertices (double circles) - convolutions of risk factors;

- edges of a graph, originating from non-terminal vertices - initial variables of the rule database $\left(y_{1}, y_{2}, y_{3}\right.$, $\left.y_{4}, y_{5}, y_{6}\right)$;

- convolutions $f_{Y_{1},} f_{Y_{2}}, f_{Y_{3}}, f_{Y_{4}}, f_{Y_{5}}, f_{Y_{6}}, f_{R}$ are made by logical conclusion based on fuzzy knowledge bases of Mamdani type.

Fuzzy model of risk assessment of production and economic activity of oil and gas production enterprises in conditions of the uncertainty of the business environment is realized by 7 systems of fuzzy conclusion: 1) $Y_{1}$ - fuzzy system of modelling of factors of production and technological risk;

2) $Y_{2}$ - fuzzy system for modelling of human influence as a risk factor;

3) $Y_{3}$ - fuzzy system of modelling of information risk factors;

4) $Y_{4}$ - fuzzy system of modelling of environmental risk factors;

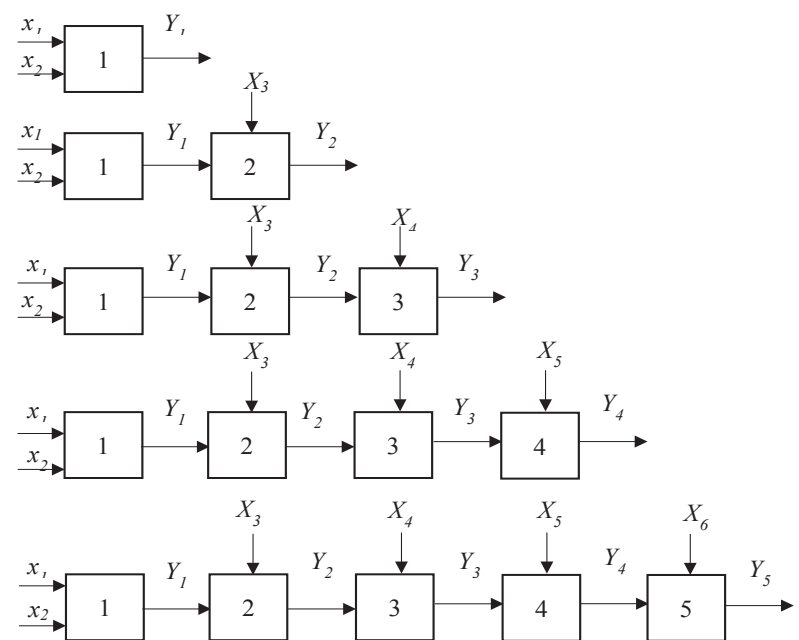

Fig. 5. Cascade model structure for the modelling of risks Source: authors' own development

5) $Y_{5}$ - fuzzy system of modelling of the geological risk factors;

6) $Y_{6}$ - fuzzy system of modelling of economic risk factors;

7) $R$ - fuzzy system of prediction of risk of oil and gas production enterprises.

Simulation modelling of the developed method of assessment of risks of oil and gas production enterprises is carried out by the software module Fuzzy Logic Toolbox for MATLAB 6.5. For visualization of Mamdani's fuzzy conclusion in the Rule Viewer and creation of "inputoutput" surfaces for the Mamdani Knowledge Base in the Surface Viewer, when the number of input factors is $2 \div 6$, a cascade model structure for the modelling of risks (Fig. 5) and a simulation model have been created in Matlab + Simulinc (Fig. 6).

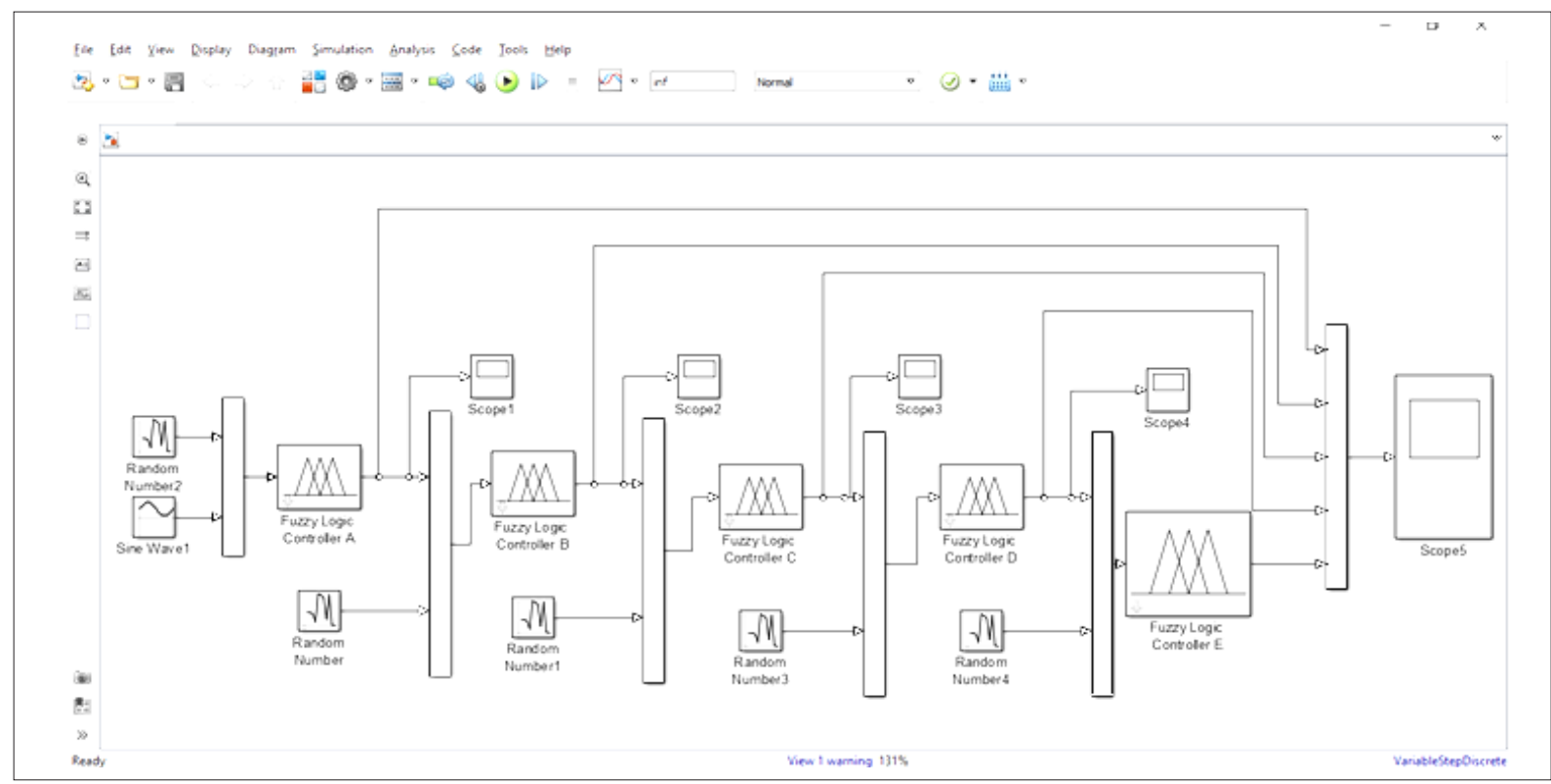

Fig. 6. A simulation model for investigating the risks of oil and gas production enterprises with the use of the cascade model structure 
Figure 7 shows the visualization windows of "inputoutput" surfaces for the Mamdani Knowledge Base in the Surface Viewer, obtained at the outputs of the simulation model Scope 1, Scope 2, Scope 3, Scope 4, Scope 5.

It should be noted that the model of assessment of risks of production and economic activity of oil and gas production enterprises is based only on expert data; therefore, there may be a discrepancy between the theoretical results of the fuzzy conclusion and the expert data. In order to ensure the higher accuracy of results, parametric identification of the fuzzy model must be carried out on the basis of experimental data of industrial researches.
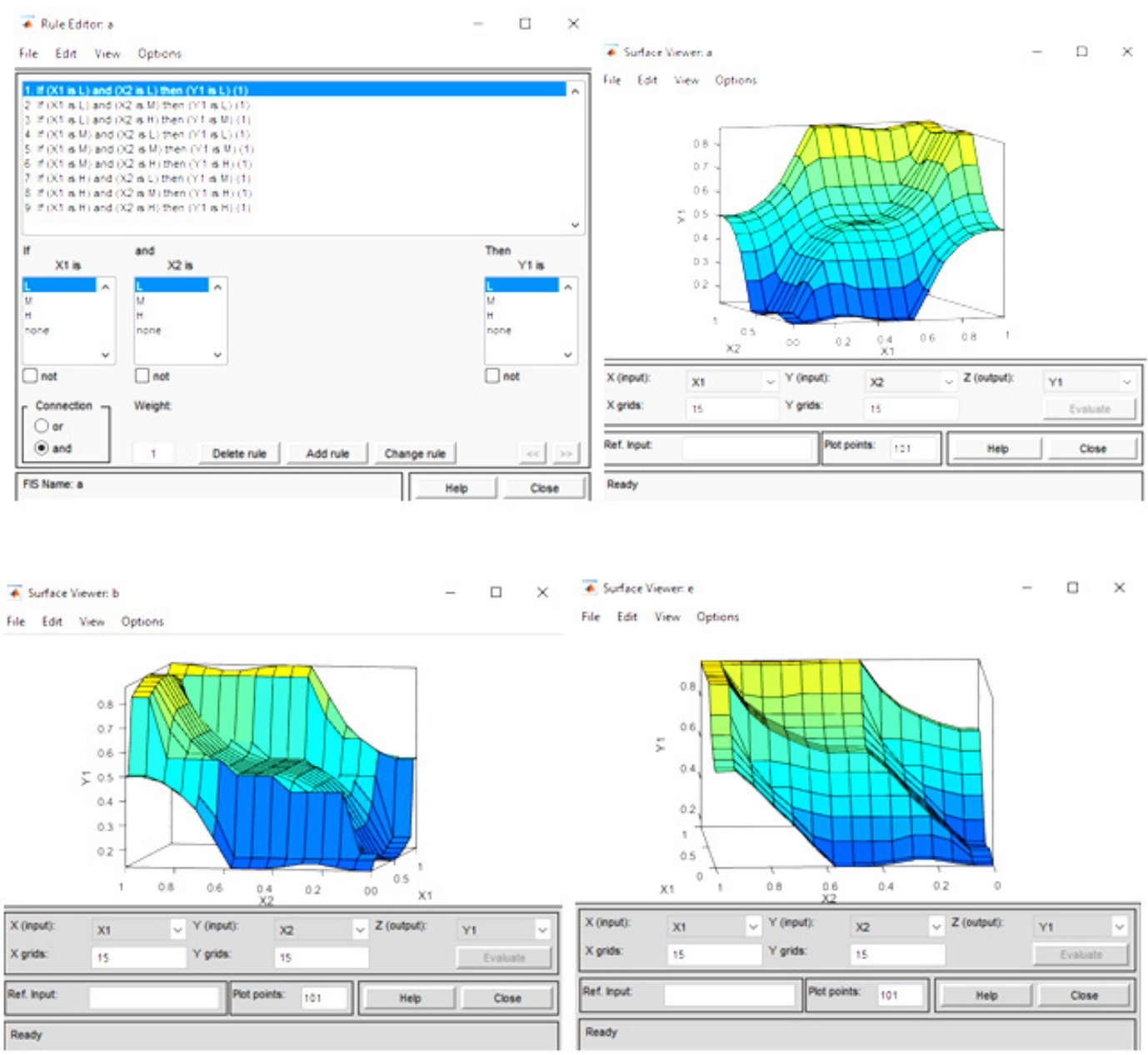

- Surtace viener.

$\square \times$ File Eda View Option
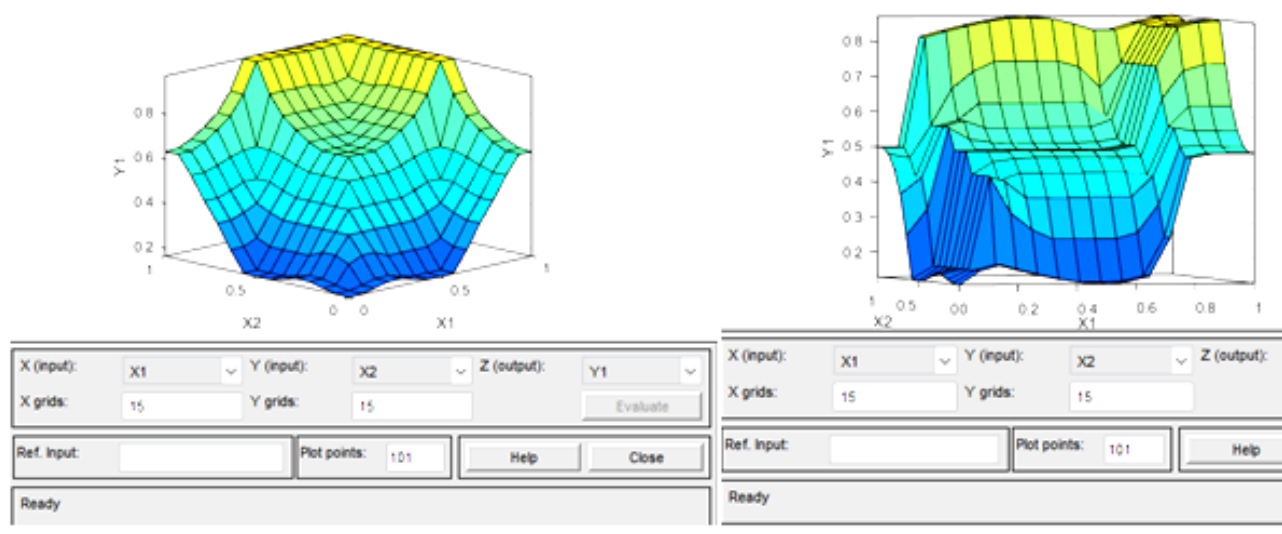

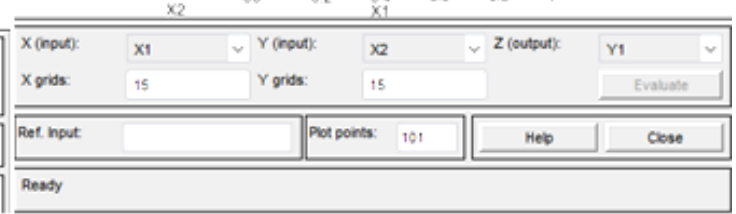

Fig. 7. Surfaces "input-output" for the Mamdani Knowledge Base in the Surface Viewer, obtained at the outputs of the simulation model Scope 1, Scope 2, Scope 3, Scope 4, Scope 5

Source: the authors' own development 


\section{Conclusions}

According to the results of our research, we have developed a cascade model of assessment of risks of activities of oil and gas production enterprises. In conclusion, we note several important points. Firstly, the main advantage of this approach is that it can remove the restrictions on the number of input variables and effectively use both quantitative and qualitative estimates of input parameters, each of which can be obtained from an individual specialist. Secondly, the fuzzy logic mechanism also allows taking into account the reliability and quality of the input information through the weight of the rules. Despite the complexity of the mathematical apparatus, risk assessment on the basis of the theory of fuzzy sets makes it possible to create a sufficiently flexible model, which will operate with a large number of input arguments and give as a resultant variable a value, which can be considered to be objective with some degree of approximation. We consider it necessary to implement the developed model of risk assessment in the risk management system of oil and gas production enterprises.

\section{References:}

Babak, I. N. (2008). Method of the project analysis in view of risk factors cause-effect relationship (Candidate dissertation, Kharkiv Aviation Institute, 2008). Dissertation Abstracts.

Gryniuk, O. I. (2016). Theoretical and applied aspects of identification of activity risks of oil and gas enterprises. Economic Analysis. 25(2), 64-78.

Leonenkov, A. V. (2005). Fuzzy modeling in MATLAB environment and fuzzyTECH, St. Petersburg: BHV-Petersburg.

Nikolaychuk, M. V. (2013). Development of a mechanism for strategic management of financial risks at enterprises. Journal of Economy and entrepreneurship, 7(2), 151-157. Retrieved from: http://naukarus.com/razrabotkamehanizma-strategicheskogo-upravleniya-finansovymi-riskami-na-predpriyatiyah

Pupkov, K. A., Egupov, N. D., \& Gavrilov, A. I. (2002). Methods of robust, neuro-fuzzy and adaptive management. Moscow: MGTU im. Baumana.

Rutkovskaya, D., Pilinskiy, M., \& Rutkovskiy, L. (2006). Neural networks, genetic algorithms and fuzzy systems. Moscow: Goryachaya liniya - Telekom.

Seredyuk, V. B. (2011). Application of neural networks and fuzzy models to determine the creditworthiness of the borrower (an individual). Odes'kyi Politechnichnyi Universytet. Pratsi. 3(37), 216-221.

Shtovba, S. D. (2007). Designing of fuzzy systems using MATLAB. Moscow: Goryachaya liniya - Telekom.

Uskov, A.A., \& Kuzmin, A.V. (2004). Intelligent management technologies. Artificial neural networks and fuzzy logic. Moscow: Goryachaya liniya - Telekom.

Yakupova, N. M., Magomedova, Z. I. (2008). Model of risk controlling in the system of strategic enterprise management. Economic science. 5(42), 317-322. Retrieved from: http://ecsn.ru/files/pdf/200805.pdf

Zadeh, Lotfi Asker. (1996). Fuzzy sets, fuzzy logic, and fuzzy systems: selected papers. Edited by George J. Klir \& Bo Yuan. Singapore; River Edge, N. J.: World Scientific.

\section{Марина ФАДЕЕВА, Оксана ГРИНЮК}

\section{НЕЧЕТКОЕ МОДЕЛИРОВАНИЕ ОЦЕНКИ РИСКОВ ДЕЯТЕЛЬНОСТИ НЕФТЕГАЗО-} ДОБЫВАЮЩИХ ПРЕДПРИЯТИЙ

Аннотация. Целью работы является разработка нечеткой модели оценки рисков деятельности нефтегазодобывающих предприятий. Методика. В связи с большим количеством факторов, влияющих на вероятность наступления рисков и с целью получения комплексного показателя в работе нами применена нечеткая каскадная модель типа Мамдани. Результаты исследования. В условиях нестабильности и перманентной неопределенности процессов добычи нефти и газа идентификация и прогнозирование наступления рисков операционной деятельности нефтегазодобывающих предприятий традиционными математическими методами моделирования не дают необходимой достоверности и точности прогнозирования. В связи с этим нами предложено интегральное оценивание и применения методологии нечеткой логики для получения необходимых результатов для принятия эффективных управленческих решений. Несмотря на сложность математического аппарата, оценивание рисков на основе теории нечётких множеств позволяет создать достаточно гибкую модель, которая будет оперировать большим количеством входных аргументов и давать в качестве результирующей переменной значение, которое можно считать объективным с некоторой степенью приближения. Практическое значение. Пошаговое добавление каждой группы риск-образующих факторов модели позволяет получить достоверные результаты вероятности наступления рисковых ситуаций в режиме реального времени, что значительно снижает убытки предприятия. Значение/оригинальность. По итогам проведенного исследования впервые разработана нечеткая каскадная модель оценки рисков деятельности нефтегазодобывающих предприятий типа Мамдани. 